\title{
Influence of habitat condition on shallow rocky reef fish community structure around islands and headlands of a temperate marine protected area
}

\author{
Z. Quaas ${ }^{1}$, D. Harasti ${ }^{2, *}$, T. F. Gaston ${ }^{1}$, M. E. Platell ${ }^{1}$, C. J. Fulton ${ }^{3}$ \\ ${ }^{1}$ School of Environmental and Life Sciences, The University of Newcastle, PO Box 127, Ourimbah NSW 2258, Australia \\ ${ }^{2}$ Fisheries Research, NSW Department of Primary Industries, Taylors Beach, NSW 2315, Australia \\ ${ }^{3}$ Research School of Biology, The Australian National University, Canberra, ACT 2601, Australia
}

\begin{abstract}
Rocky reef fish assemblages in coastal areas are under increasing pressure from a range of human activities, including extraction via recreational and commercial fishing. Within Australia, spatial management of fish assemblages aims to protect habitats and regulate harvest pressure via the use of no-take areas (NTAs), where no extraction is permitted, and partially protected areas (PPAs), where limited fishing is allowed but higher impact activities (e.g. trawling) are prohibited. We used a novel combination of mini-baited remote underwater video (mini-BRUV) systems and in situ microhabitat assessments to assess whether reef fish community structure on shallow (6-9 m) rocky reefs varied with spatial management zone (NTAs versus PPAs), sampling season (autumn, spring) and benthic habitat condition around coastal islands and headlands within the Port Stephens-Great Lakes Marine Park (established in 2007). While fish community composition and the relative abundance of fish species did not differ significantly across spatial management zones, there were significant differences among sampling season, and spatial variation at the site level that was partly explained by geomorphology (island/headland). Notably, there was a strong association between variation in fish community structure and site-level cover of canopyforming macroalgae among islands and headlands, which transcended management zones. Our study suggests that balancing habitat condition and geomorphological setting (islands, headlands) among management zones is key to the conservation and management of shallow-water reef fish assemblages. In particular, the percent cover of canopy-forming macroalgae may be a key habitat indicator for designing, monitoring and rebalancing spatial management zones.
\end{abstract}

${ }^{*}$ Corresponding author: david.harasti@dpi.nsw.gov.au

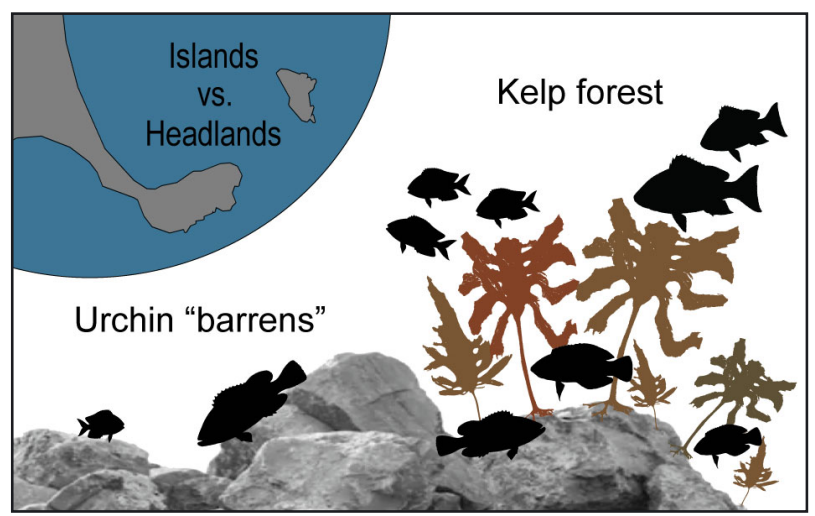

Habitat condition and reef position near islands or headlands were key predictors for fish community structure on shallow rocky reefs.

Photo: Chris Fulton

KEY WORDS: BRUVs - Habitat quality - Kelp · Marine protected areas · Partially protected areas

\section{INTRODUCTION}

Marine protected areas (MPAs) have been established as spatially managed regions to provide balance in our use of marine estates while conserving marine biodiversity (Edgar et al. 2007, Lester et al. 2009, Miller \& Russ 2014). Typically, MPAs are designed for multiple users via regulated zones that have varying levels of protection from extractive activities while addressing specific environmental and

() The authors 2019. Open Access under Creative Commons by Attribution Licence. Use, distribution and reproduction are unrestricted. Authors and original publication must be credited. 
socio-economic objectives (Day 2002, Habtemariam \& Fang 2016). No-take areas (NTAs) provide the highest level of protection and provide an indication of how different species respond to cessation of extractive activities (Lester et al. 2009). NTAs are recognised as one tool that can often contribute to minimising impacts on target fishery species and improve essential habitats that species rely on (Gaines et al. 2010, Sciberras et al. 2015). The effectiveness of NTAs is known to vary in relation to their size, location, compliance effort and time since implementation (Edgar et al. 2014, Malcolm et al. 2016).

In well-managed NTAs, fish assemblages have shown a range of responses to the cessation of extractive activities, including the restoration of overexploited stocks and biodiversity via the recovery of target species and ecological communities inside reserves (Lester et al. 2009, Babcock et al. 2010, Boubekri \& Djebar 2016). It has been demonstrated that NTAs can lead to an increase in abundance, biomass and size of fishes (Halpern 2003, Malcolm et al. 2018), as well as increase production, export adults and recruits to neighboring non-reserve areas (spillover) and increase trophic interactions (Shears \& Babcock 2002, Russ et al. 2003, 2005, Halpern 2003, Lester et al. 2009, Russ \& Alcala 2011). The time scales for population recovery to virgin biomass can vary from years to at least decades, depending on the life cycle of the impacted species (i.e. typically ranging from 15 to $45 \mathrm{yr}_{i}$ Halpern \& Warner 2002, Russ et al. 2003, Russ \& Alcala 2004, Noble et al. 2013, Kaplan et al. 2019). Whilst there is little doubt that initial rates of recovery are possible for certain species within ecosystems, it is clear that the recovery process of reserves is complex and influenced by a variety of biotic and abiotic factors, such as the recovery of benthic habitat, which indirectly increases fish abundance within reserves and adjacent areas (Russ et al. 2005, Molloy et al. 2009, Harasti et al. 2018a).

Functional linkages between habitat and marine community composition suggest that the presence of differing habitats can be a primary driver of reef fish assemblage structure (Rodwell et al. 2003, Noble et al. 2013, Miller \& Russ 2014). Through selectivity by individuals seeking shelter and/or food, species may associate with certain habitat types such that changes in habitat quality and quantity translate to variations in fish distribution and abundance across the seascape (Coleman et al. 2016, Fulton et al. 2016). Benthic habitat formers, such as canopy-forming macroalgae, seagrass, sponges and corals, create key habitats that support juvenile and adult reef fish spe- cies (Teixeira-Neves et al. 2015, Smith \& Anderson 2016, van Lier et al. 2017, Wilson et al. 2017). With habitat loss affecting both conservation and harvest use of our coastal areas, there is a strong need to understand the role of habitat condition to facilitate and enhance fish biodiversity, abundance and replenishment (Rodwell et al. 2003, Noble et al. 2013). Of critical importance, then, is ensuring that spatial zones that aim to protect a suite of species include their necessary habitat types within their borders and that these habitat types are understood (Malcolm et al. 2007, Fulton et al. 2016).

In shallow coastal waters of New South Wales (NSW), Australia, there are relatively few studies that have undertaken a combined assessment of habitat characteristics and potential NTA effects on the distribution and abundance of rocky reef fish assemblages using remote video techniques that can identify species and abundances of fishes that react adversely to divers. Using deployments of minibaited remote underwater video (mini-BRUV) systems in concert with fine-scale assessment of reef habitat condition in shallow waters $(6-9 \mathrm{~m})$, this study aimed to determine the spatial community structure of reef-associated fishes with respect to management zones (NTAs and nearby PPAs) and habitat condition within the Port Stephens-Great Lakes Marine Park in NSW. The zoning plan for the park commenced in 2007, which was around $10 \mathrm{yr}$ prior to the current surveys. We also included 2 sampling periods (austral autumn and spring) to explore potential for temporal variation in fish community structure. A key novelty was the spatial coupling of remote video with local habitat conditions assessments, which allowed us to compare fine-scale variation in benthic habitat availability with reef fish community structure across different management zones and sites.

\section{MATERIALS AND METHODS}

\subsection{Study region}

The Port Stephens-Great Lakes Marine Park (PSGLMP; $32^{\circ} 43^{\prime} 04.63^{\prime \prime} \mathrm{S}, 152^{\circ} 08^{\prime} 29.27^{\prime \prime} \mathrm{E}$ ) is the largest of 6 multiple-use marine parks in NSW (Fig. 1), for which a zoning plan was implemented in April 2007 (NSW Marine Parks Authority 2013). Approximately 98000 ha in size, the PSGLMP encompasses a diverse range of subtidal estuarine and marine habitats such as seagrass, sponges, soft corals and rocky reef mosaics of macroalgae-dominated 


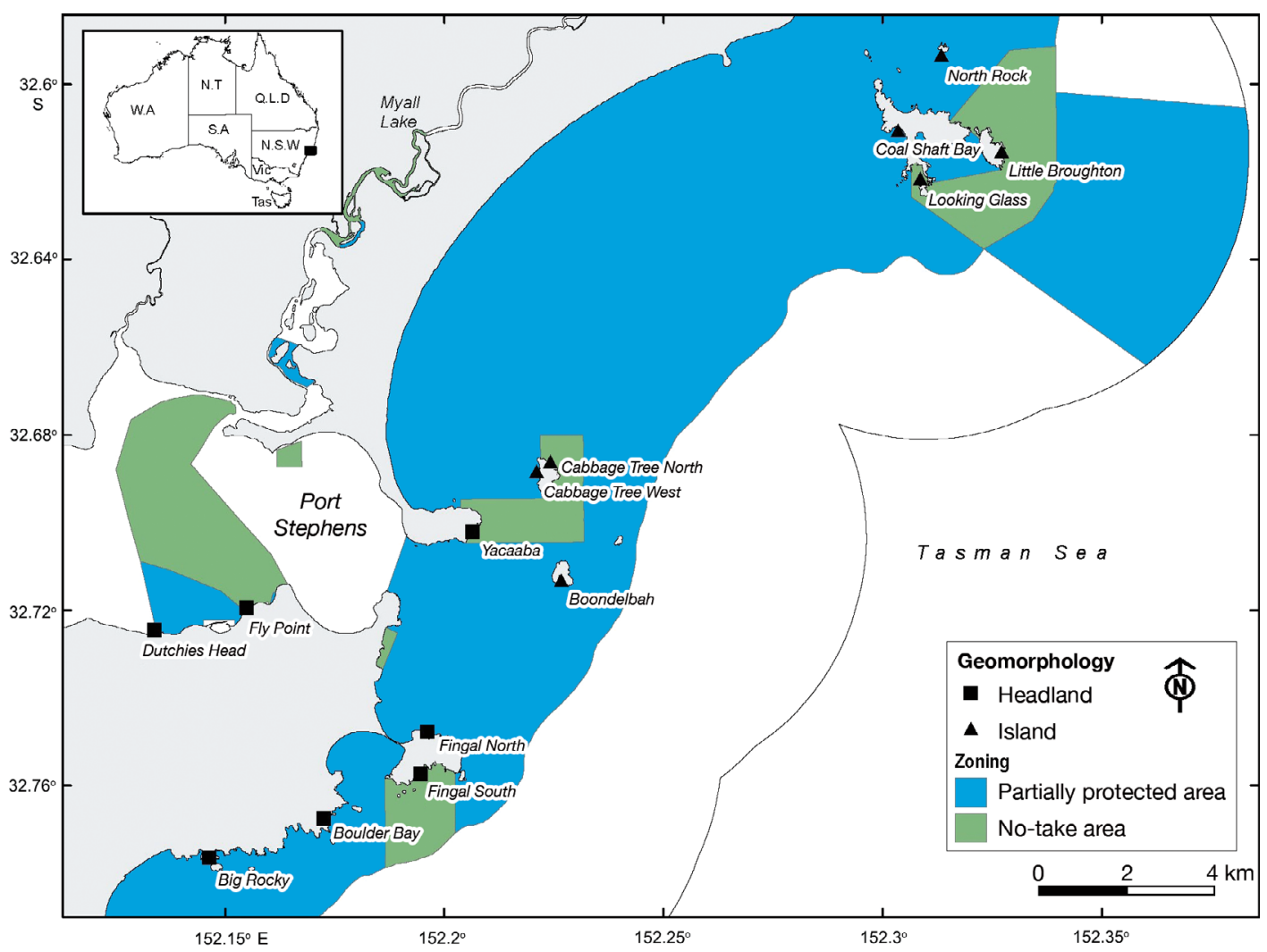

Fig. 1. Location of study sites among islands $(\mathbf{\Delta})$ and headlands $(\boldsymbol{\square})$ in differing levels of protection (partially protected and notake) within the Port Stephens-Great Lakes Marine Park (offshore marine park boundary indicated by black line), New South Wales, Australia

patches and urchin barrens that support distinct groups of marine wildlife (Davis et al. 2016, Fulton et al. 2016). The rocky reefs of the marine park have been shown to be important for a range of common reef fish species and also provide protection for threatened and exploited species (e.g. snapper Chrysophrys auratus, Harasti et al. 2018b; and black cod Epinephelus daemelii, Harasti \& Malcolm 2013).

The PSGLMP includes various zones to provide different levels of protection. NTAs, also known as sanctuary zones in NSW, cover $17.5 \%$ of the PSGLMP and provide the highest levels of protection by prohibiting all extractive activities (including both commercial and recreational fishing). Partially protected areas (PPAs), known as habitat protected zones (HPZ) in NSW, cover $42 \%$ of the park and allow recreational line and commercial trap and line fishing; however, activities such as commercial trawling, longline, setline, dropline and purse seine are prohibited (Fig. 1). For this study, 14 sites were selected among islands $(n=7)$ and headlands $(n=7)$ that encompass both NTAs and PPAs within the southern section of the marine park, with fish surveys con- ducted within the depth range of 6-9 m, where there is known to be diverse reef fish assemblages (Fulton \& Bellwood 2004).

\subsection{Data collection}

Field data were collected in austral autumn (MarchMay) and spring (September-October) 2016 using mini-BRUVs coupled with underwater visual surveys of habitat condition in the mini-BRUV deployment areas. Sampling occurred between 09:00 and 14:00 h, with the sampling for each time period occurring over $2 \mathrm{wk}$. At each site, mini-BRUVS were deployed at a minimum of $30 \mathrm{~m}$ apart by scuba divers working along a $200 \mathrm{~m}$ transect that ran parallel to the shoreline. Each of the mini-BRUVs incorporated a single high-definition GoPro HERO video camera $(2,3$ and 4 : www.gopro.com) in an underwater housing mounted above a lead weight that was attached to a $30 \mathrm{~cm}$ long pole at the end of which was mounted a bait basket (as per Harasti et al. 2014). This compact design allowed for cameras to be placed within the 
complex kelp canopy and boulder habitats that were typical of these shallow reefs. Small stereo miniBRUVs were not available at the time of this project and also would have been logistically difficult to deploy using the diver placement method. Only a small amount of bait, consisting of 3 individual pilchards Sardinops neopilchardus, was deployed to minimise bait dispersal as the aim was to attract fish from the immediate area $\left(\sim 15 \mathrm{~m}^{2}\right)$. Mini-BRUVs were deployed for a total soak time of $30 \mathrm{~min}$, as $30 \mathrm{~min}$ has been shown to be an appropriate set time for BRUVs within the marine park (Harasti et al. 2015). Six miniBRUVs were deployed at each site per season, to provide an overall total of 168 mini-BRUV replicates through a repeated deployment at the same sites during both autumn (March-May) and spring (September-November).

During the autumn surveys, benthic habitat composition was visually estimated within a $10 \times 10 \mathrm{~m}$ quadrat $\left(100 \mathrm{~m}^{2}\right)$ around the mini-BRUVs deployment site by an experienced SCUBA diver hovering 3-5 $\mathrm{m}$ above the reef (Fulton et al. 2016). Twelve functional categories of habitat were recorded: 3 that comprise macroalgae, i.e. canopy (>30 $\mathrm{cm}$ canopy height, represented by Ecklonia, Sargassum and Phyllospora), foliose ( $<20 \mathrm{~cm}$ canopy height, represented by Haliptilon, Amphiroa, Delisea and Lobophora) and turfing macroalgae ( $<2 \mathrm{~cm}$ canopy height), and 5 other types of organisms that included pyurids, seagrass (Halophila ovalis), corals, urchins (Centrostephanus and Phyllacanthus) and sponges, along with 3 sediment classes (bedrock, boulder-rock and gravel-sand) following Fulton et al. (2016).

\subsection{Video analyses}

Video files from each GoPro camera were individually loaded into the SeaGIS software Eventmeasure (version 4.42) for analysis. Analysis of the video started once the diver had left the area and was not seen on the video (approximately $1 \mathrm{~min}$ ) and the $30 \mathrm{~min}$ video analysis then commenced. For each 30 min video replicate, all individual fish species were identified and the maximum number of each individual species within a single frame (MaxN) was recorded. MaxN indicates the relative abundance of species in a defined location, recording the maximum number of individuals in any frame during the recording period. This method of analysis is a conservative estimate of abundance and ensures the greatest number of individuals is documented without repetition (Cappo et al. 2004).

\subsection{Statistical analyses}

Spatial and temporal variation in the fish assemblages was assessed using a permutational multivariate analysis of variance (PERMANOVA) with the fixed factor of management zone (NTAs and PPAs) and random factors of sampling season (autumn and spring) and sites nested within management zone. Prior to these analyses, a sample-level exploration revealed 25 rare species contributed $0.025 \%$ or less of the total abundance of all fish observed (7991) and appeared in only 1 or 2 sample stations across a mixture of sites (Table S1 in the Supplement at www.intres.com/articles/suppl/m626p001_supp.pdf), so they were excluded from the multivariate analyses. Heterogeneity of dispersion among species (largely due to differences among schooling and solitary fish species) was addressed by dispersion weighting each species. PERMANOVA was then conducted using Type III sum of squares and a maximum of 9999 permutations of a resemblance matrix based on the modified Gower (base 2) dissimilarity measure, which weights a doubling in species abundance as similar to a shift in species presence/absence across sample pairs (Anderson et al. 2006, 2008). An independent contrast of 2 groups of sites corresponding to islands and headlands was used to explore the influence of geomorphology within the significant terms involving the site factor. Testing of this model revealed a very high p-value for zone (Table S2) and a negative estimate of the component of variation, so the PERMANOVA was run again with the zone term pooled. This same model was re-run for offshore samples only (i.e. excluding the 2 inshore headland sites), and for a subset of 7 fishery target species to confirm consistency of the main effects (Tables S3 and S4). Significant interaction terms were then explored using threshold-metric multi-dimensional scaling (tmMDS) ordination of group centroids. Species richness $(S)$ and evenness (Peilou's $J^{\prime}$ ) were also used to explore site-level seasonal variations in fish community structure. Key species responsible for any variation across both spatial and temporal scales were identified with the similarity percentage routine (SIMPER; Clarke \& Warwick 2001), performed for each of the factors (site and season) using the modified Gower (base 2) distance matrices on dispersion-weighted data for individuals contributing greater than $70 \%$ to the total samples. Relative abundances (MaxN) of key species driving dissimilarity across sites and seasons were then visually compared using box plots.

Variation in habitat condition around each miniBRUV sample station was examined during the 
autumn sampling season (habitat data were not available for all sites in spring as some sites could not be dived safely because of adverse sea conditions) using a 2-factor PERMANOVA with zone as a fixed factor and site (nested within zone) as a random factor, and a contrast of sites arranged into the 2 groups of headlands and islands within the same model. This test was performed using Type III sum of squares (to account for model asymmetry) and 9999 permutations of a Bray-Curtis resemblance matrix of the square-root transformed percent cover data of habitat types summed into 11 functional groups (canopy, foliose and turf macroalgae, pyurids, coral, sponge, urchins, seagrass, bedrock, boulderrock and gravel-sand).

Variations in habitat condition among sites and geomorphology were then explored with a tmMDS of site group centroids. Relationships between habitat condition and fish assemblage structure during autumn was examined using a 2 -factor permutational multivariate analysis of covariance (PERMANCOVA; Anderson et al. 2008), with percent cover of canopy-forming macroalgae (being the sum of Ecklonia, Phyllospora and Sargassum cover) as a covariate, as this is a key proxy for major differences in patch habitat condition (kelp forest versus boulder-coral) in this region (Fulton et al. 2016). Effects of the fixed factor of management zone and random factor of site nested within zone was tested using Type I sum of squares and 9999 permutations of residuals under a reduced model of a modified
Gower (base 2) resemblance matrix of dispersionweighted fish survey data. Significant effects were explored further by mapping hierarchical clusters within the fish community resemblance matrix onto a principal coordinates (PCO) ordination (Anderson et al. 2008). Vector overlays were applied to explore interactions between fish community clusters, key fish species, and components of the benthic habitat type around each mini-BRUVS deployment that correlated strongly with the ordination structure (Pearson's $r>0.5$ ).

All analyses were performed using PRIMER-E (Plymouth Routines in Multivariate Ecological Research) version 6.1.15 (Clarke \& Warwick 2001), with additional software package PERMANOVA+ version 1.0.5 (Anderson et al. 2008).

\section{RESULTS}

\subsection{Spatial and seasonal variation in reef fish community structure}

Throughout the study duration, 107 species of fish (45 families) were recorded across all sites. This total was represented by the Class Actinopterygii, making up 96 species ( 35 families), and 11 species (10 families) of the Chondrichthyes (full species list in Table S1). Fish assemblage structure differed significantly between seasons and sites, with a significant 2 -way site $\times$ season interaction, and a significant difference between the 2 groups of

Table 1. Summary of PERMANOVA main test of reef fish community structure among sampling seasons (autumn and spring), and sites (14 sites nested within zones) within the Port Stephens-Great Lakes Marine Park, with the zone term pooled in the model (see Table S2 in the Supplement for full model). Test was based on dispersion-weighted relative abundance (MaxN) of abundant fish species arranged into a modified Gower (base 2) resemblance matrix, with over 9600 permutations (except the independent contrast of Geomorphology(Zone) groups, which had 2382 unique permutations) with Type III sum of squares. An independent contrast of 2 groups of sites (islands versus headlands) was included to explore the influence of geomorphology within the significant terms involving the site factor. Significant terms $(p<0.05)$ are indicated in bold

\begin{tabular}{|lrcccr|}
\hline Source & SS & MS & df & Pseudo- $F$ & p (perm) \\
\hline Season & 4.186 & 4.186 & 1 & 4.174 & $\mathbf{0 . 0 0 1}$ \\
Site(Zone) & 39.967 & 3.331 & 12 & 3.321 & $<\mathbf{0 . 0 0 1}$ \\
Geomorphology(Zone) & 6.317 & 3.159 & 2 & 3.511 & $\mathbf{0 . 0 4 3}$ \\
Zone $\times$ Season & 1.449 & 1.449 & 1 & 1.445 & 0.141 \\
Site(Zone) × Season & 12.034 & 1.003 & 12 & 1.912 & $<\mathbf{0 . 0 0 1}$ \\
Geomorphology(Zone) & 1.799 & 0.900 & 2 & 1.227 & 0.147 \\
$\quad \times$ Season & 75.017 & 0.532 & 141 & & \\
Pooled & 132.51 & & 167 & & \\
Total & & & & & \\
\hline
\end{tabular}

sites around islands versus headlands (Table 1). Unconstrained ordination revealed the greatest variability among fish communities of estuarine (Fly Point and Dutchies Head) and offshore sites, followed by sampling time among the 2 inshore sites and some offshore sites spread across island and headlands (e.g. Yacaaba Head, Cabbage Tree Island North, Boondelbah Island), none of which was aligned with spatial management zone (Fig. 2). Estimates of the components of variation indicated that 44.0, 19.7 and $28.2 \%$ could be attributed to the significant site, season and site $\times$ season terms, respectively. The independent contrast of sites around island versus headlands suggested $23.1 \%$ of sitelevel variation could be attributed to difference in geomorphology. The ex- 


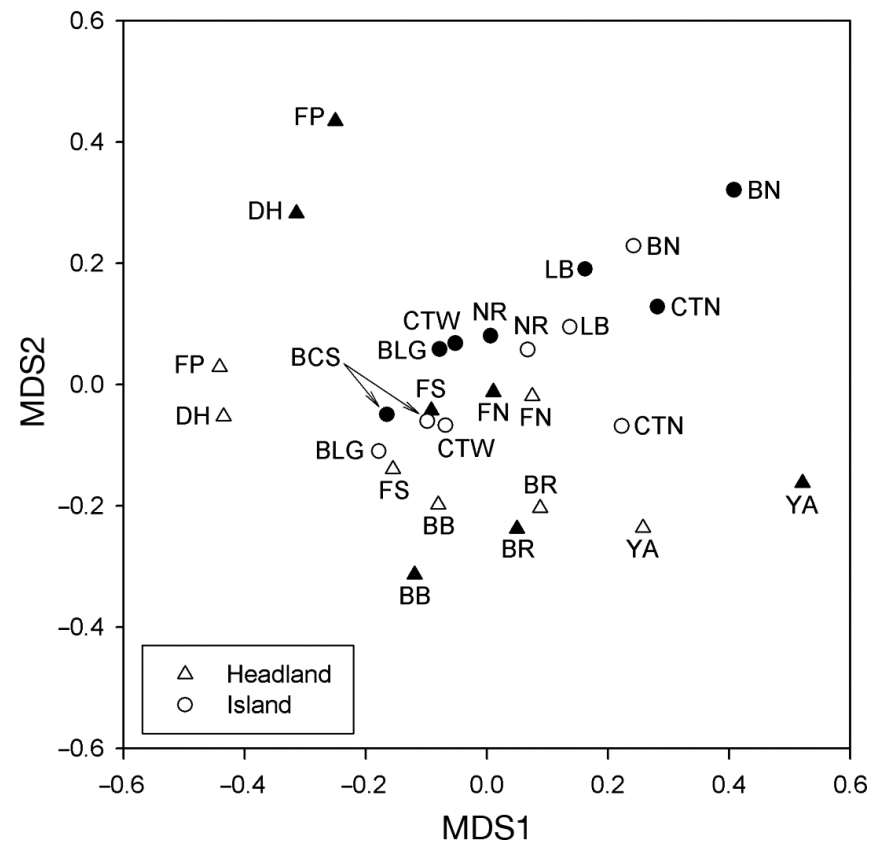

clusion of samples from the 2 distinct estuarine sites did not change the significance of main effects or interaction terms (Table S3).

Higher fish species richness was detected across sites during autumn, with the exception of Coal Shaft Bay (PPA) and Cabbage Tree North (NTA), with the highest species richness in North Rock (PPA), Fingal North (NTA) and Fly Point (NTA, Fig. 3A). Fish com-
Fig. 2. Threshold-metric multi-dimensional scaling (MDS) of group centroids for the significant site by season interaction in reef fish community structure (based on relative abundance, MaxN) across sites in the Port Stephens-Great Lakes Marine Park. Note: group centroids across the 2 sampling seasons (autumn: filled symbols; spring: open symbols) tend to pair closely for each site, with the exceptions of the inshore estuary sites (Fly Point and Dutchies Head), Yacaaba Head, Cabbage Tree Island North and Boondelbah Island. Site name abbreviations: BB: Boulder Bay; BCS: Broughton Island Coal Shaft; BLG: Broughton Island Looking Glass; BN: Boondelbah Island; BR: Big Rocky Headland; CTN: Cabbage Tree Island North; CTW: Cabbage Tree Island West; $\mathrm{DH}_{;}$Dutchies Head; FN: Fingal Head North; FP: Fly Point; FS: Fingal Head South; LB: Little Broughton Island; NR: North Rocks Island; YA: Yacaaba Headland

munity evenness was generally lower during autumn, with the exception of North Rock and Boulder Bay (Fig. 3B). As such, there was no clear evidence of a latitudinal gradient or zoning effects on fish community structure across the 14 sites, with variations in species richness and evenness among adjacent sites of similar or greater magnitude than among sites separated from the far north (North Rock and Little
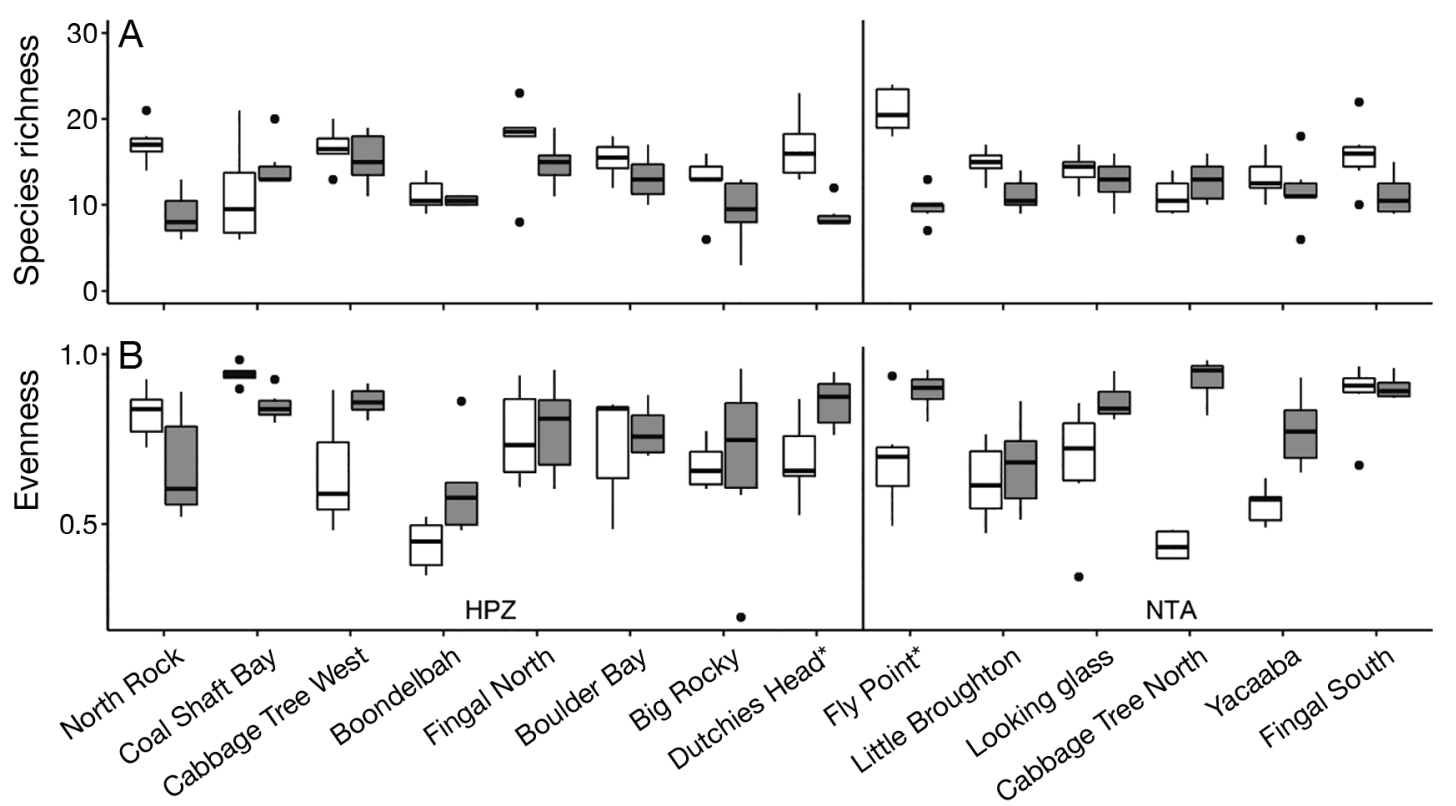

Fig. 3. Reef fish community structure in terms of (A) species richness and (B) Peilou's evenness across the 14 sites during each sampling season (autumn: light box; spring: dark box). Sites are arranged along the $x$-axis in order of latitude from north (left) to south (right). Boxes represent the lower and upper quartiles, with a median line. Whiskers represent the $95 \%$ lower and upper extremes with dot outliers. HPZ: habitat protected zone; NTA: no-take area; asterisks indicate the 2 inshore headlands 
Broughton) to far south (Boulder Bay and Big Rocky; Fig. 3). SIMPER analysis revealed Atypichthys strigatus, Ophthalmolepis lineolatus and Gymnothorax prasinus were the 3 most influential species driving variation between seasons of the 22 species contributing greater than $70 \%$ to the total samples (Table 2). Both A. strigatus and G. prasinus were more abundant in autumn (A. strigatus: mean $\pm \mathrm{SE}=$ $28.4 \pm 0.3$ autumn versus $9.6 \pm 0.17$ spring; $G$. prasinus: $1.7 \pm 0.01$ versus $1.3 \pm 0.01$ ), whilst $O$. lineatus was more abundant in spring $(3.5 \pm 0.03)$ versus autumn (3.1 \pm 0.02$)$ (Fig. 4). Other species that were seen to show large seasonal differences and that were more abundant in autumn were Trygonorrhina fasciata, Rhabdosargus sarba, Trachurus novaezelandiae, Pseudolabrus guentheri and Brachaelurus waddi (Fig. 4). The one species that was found to be more significantly abundant in winter was the bottomdwelling horn shark Heterodontus portusjacksoni (Fig. 4). The SIMPER analysis also indicated that the contributing species are a mixture of target and nontarget fishery species. An analysis focused only on fishery target species confirmed the same main effects as for the main PERMANOVA above, including no significant difference between management zones (pseudo- $F_{1,167}=0.797, \mathrm{p}=0.690$ ) on these shallow rocky reefs (Table $\mathrm{S} 4$ ).

\subsection{Habitat condition and reef fish community structure}

Habitat condition varied significantly across sites (pseudo- $F_{12,83}=6.036, \mathrm{p}<0.001$ ), and among the headland and island site groups (pseudo- $F_{2,83}=$ $3.749, \mathrm{p}<0.01$ ), but not among the 2 management zones (pseudo- $F_{1,83}=0.899, p=0.465$ ) during autumn. An unconstrained ordination of the site group centroids confirmed strong overlap among sites of different zoning; however, there was some differentiation between headland and island sites, particularly in terms of percent cover of canopy macroalgae (Fig. 5). This variation in percent cover of canopy macroalgae was a significant covariate for the structure of reef fish assemblages during autumn, particularly among sites of varying geomorphology (islands versus headlands; Table 3). Estimates of the components of variation indicated that 10.8 and 56.6 , and $28.0 \%$ could be attributed to the significant canopy, site, and geomorphology effects, respectively, while 17.2 and $24.4 \%$ of the variation in autumn fish community structure could be attributed to the significant canopy $\times$ site and canopy $\times$ geomorphology interactions. With the significant terms involving site, 28 and $24.4 \%$ of variation could be attributed to geomorphology (island

Table 2. Similarity percentage (SIMPER) analysis of the fish species contributing the most dissimilarity between seasons (autumn and spring). Species abundance is square-root transformed, and percentages are given for season dissimilarity, individual species contributions and cumulative counts. The cut-off for fish species contributions was $70 \%$

\begin{tabular}{|c|c|c|c|c|c|c|}
\hline Species & $\begin{array}{l}\text { Average } \\
\text { Autumn }\end{array}$ & $\begin{array}{l}\text { undance } \\
\text { Spring }\end{array}$ & $\begin{array}{c}\text { Average } \\
\text { dissimilarity }\end{array}$ & $\begin{array}{c}\text { Dissimilarity/ } \\
\text { SD }\end{array}$ & $\begin{array}{c}\text { Contribution } \\
(\%)\end{array}$ & $\begin{array}{c}\text { Cumulative } \\
(\%)\end{array}$ \\
\hline Atypichthys strigatus & 2.83 & 0.98 & 5.85 & 1.16 & 10.08 & 10.08 \\
\hline Ophthalmolepis lineolatus & 3.12 & 3.45 & 4.94 & 1.07 & 8.5 & 18.58 \\
\hline Gymnothorax prasinus & 1.71 & 1.29 & 2.7 & 1.1 & 4.65 & 23.23 \\
\hline Scorpis lineolata & 1.16 & 0.81 & 2.53 & 0.61 & 4.35 & 27.59 \\
\hline Chrysophrys auratus & 1.13 & 0.31 & 2.47 & 0.75 & 4.25 & 31.83 \\
\hline Acanthistius ocellatus & 0.76 & 0.74 & 1.9 & 0.84 & 3.27 & 35.11 \\
\hline Parma microlepis & 0.83 & 0.38 & 1.74 & 0.89 & 2.99 & 38.1 \\
\hline Notolabrus gymnogenis & 1.5 & 1.54 & 1.64 & 0.97 & 2.83 & 40.93 \\
\hline Parma unifasciata & 0.92 & 0.8 & 1.61 & 0.65 & 2.78 & 43.71 \\
\hline Scorpaena jacksonesis & 0.68 & 0.36 & 1.54 & 0.94 & 2.65 & 46.36 \\
\hline Heterodontus portusjacksoni & 0.1 & 0.49 & 1.4 & 0.59 & 2.41 & 48.76 \\
\hline Trachurus novaezelandiae & 0.57 & 0.21 & 1.36 & 0.47 & 2.34 & 51.1 \\
\hline Hypoplectrodes maccullochi & 0.54 & 0.36 & 1.3 & 0.75 & 2.25 & 53.35 \\
\hline Pseudolabrus guentheri & 0.79 & 0.51 & 1.3 & 0.81 & 2.24 & 55.58 \\
\hline Parupeneus spilurus & 0.43 & 0.49 & 1.29 & 0.61 & 2.21 & 57.79 \\
\hline Chironemus marmoratus & 0.54 & 0.37 & 1.27 & 0.56 & 2.18 & 59.97 \\
\hline Cheilodactylus fuscus & 0.4 & 0.33 & 1.13 & 0.73 & 1.94 & 61.92 \\
\hline Pictilabrus laticlavius & 0.4 & 0.33 & 1.1 & 0.69 & 1.9 & 63.82 \\
\hline Trygonorrhina fasciata & 0.48 & 0.04 & 1.08 & 0.6 & 1.85 & 65.67 \\
\hline Rhabdosargus sarba & 0.32 & 0.17 & 1.04 & 0.52 & 1.79 & 67.46 \\
\hline Brachaelurus waddi & 0.31 & 0.2 & 0.93 & 0.67 & 1.59 & 69.05 \\
\hline Acanthopagrus australis & 0.37 & 0.22 & 0.92 & 0.41 & 1.58 & 70.64 \\
\hline
\end{tabular}




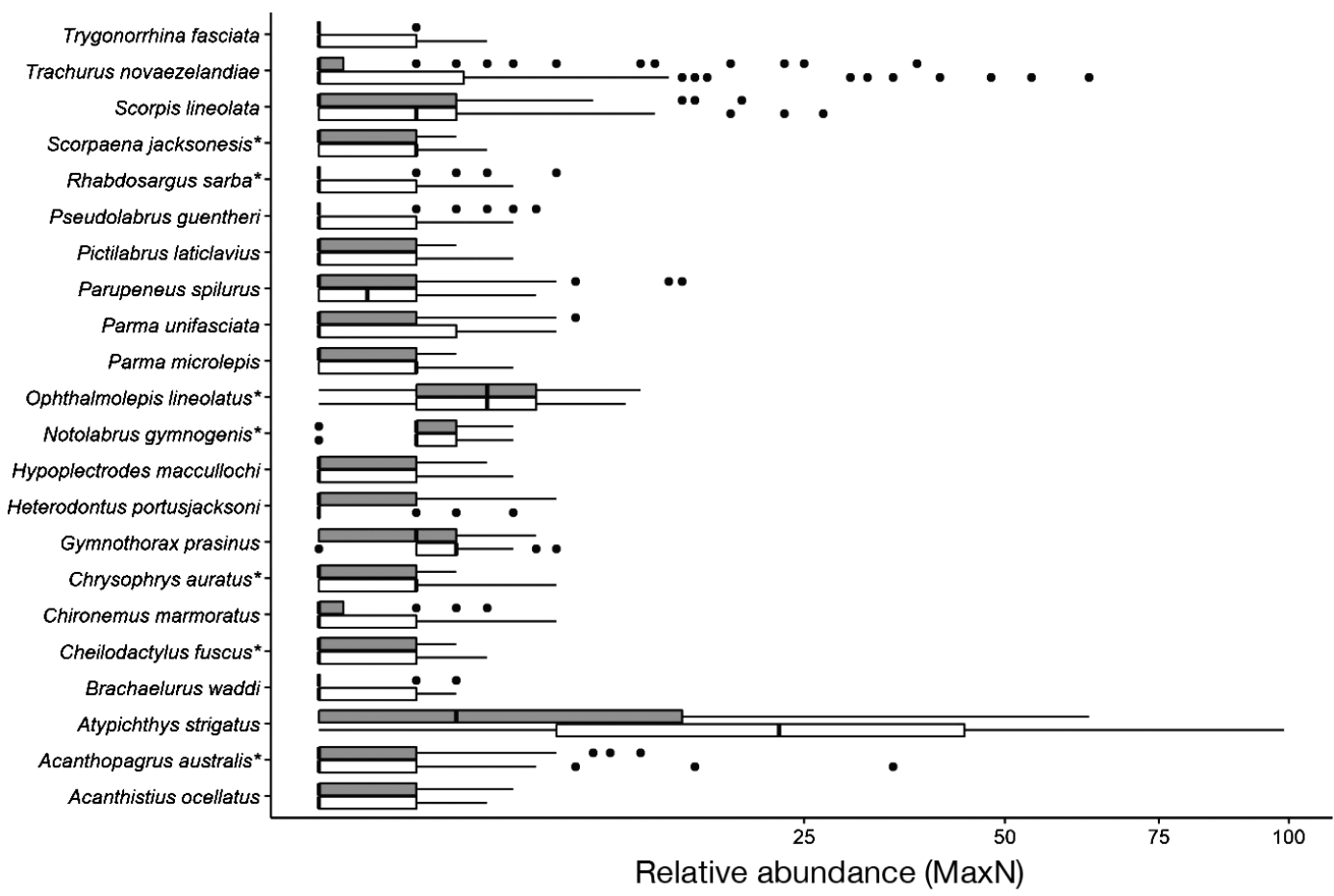

Fig. 4. Site-level relative abundance (MaxN) for fish species contributing up to $70 \%$ of community dissimilarity across the 14 sites and sampling seasons (autumn: light box; spring: dark box). Boxes represent the lower and upper quartiles, with a median line. Whiskers represent the $95 \%$ lower and upper extremes with dot outliers. ${ }^{*}$ Species that are considered target fishery species within the Marine Park based on recreational and commercial catch data

Table 3. Summary of PERMANCOVA main test of reef fish community structure (based on relative MaxN abundance) among zones (fixed, NTA and PPA) and sites (random, 14 sites nested within zone) of the Port Stephens-Great Lakes Marine Park during the autumn sampling season, with the covariate of mean percent cover of canopy-forming macroalgae around each miniBRUV sampling station. An independent contrast of 2 groups of sites (islands versus headlands) was included to explore the influence of geomorphology within the significant terms involving the site factor. Significant terms $(p<0.05)$ are indicated in bold

\begin{tabular}{|lrrrrr}
\hline Source & SS & MS & df & Pseudo-F & p (perm) \\
\hline Canopy macroalgae & 2.161 & 2.161 & 1 & 1.822 & $\mathbf{0 . 0 1 2}$ \\
Zone & 2.254 & 2.254 & 1 & 0.987 & 0.435 \\
Site(Zone) & 27.778 & 2.315 & 12 & 5.204 & $<\mathbf{0 . 0 0 1}$ \\
Geomorphology(Zone) & 4.617 & 2.309 & 2 & 3.449 & $<0.001$ \\
Canopy macroalgae $\times$ Zone & 0.685 & 0.685 & 1 & 1.540 & 0.050 \\
Canopy macroalgae $\times$ Site(Zone) & 5.976 & 0.543 & 11 & 1.222 & $\mathbf{0 . 0 2 9}$ \\
Canopy macroalgae $\times$ Geomorphology(Zone) & 2.998 & 1.499 & 2 & 2.239 & $<\mathbf{0 . 0 0 1}$ \\
Residual & 25.353 & 0.445 & 57 & & \\
Total & 64.207 & & 83 & & \\
\hline
\end{tabular}

versus headland) within the site and canopy $\times$ site interaction terms, respectively. Indeed, several major groups of similar fish community structure were detected across the replicate samples (Fig. 6). The largest group contained samples within a mixture of management zones and sites among islands/headlands, but were characterised by 2 species of labrid (Ophthalmolepis lineaolata and Notolabrus gymnogenis) and the moray eel Gymnothorax prasinus in areas dominated by canopy and/or foliose macroalgae (bottom right of Fig. 6A-C). A group contain- ing the inshore estuarine samples at Dutchies Head and Fly Point (top right in Fig. 6A) was characterised by sponge, sand and pyurid habitat (Fig. 6B) and a diversity of fish species from multiple families (Fig. 6C). Two other overlapping fish community groups contained samples from a headland site (Yacaaba), and 3 offshore island sites characterised by pyurid and boulder-coral habitat occupied by Parma unifasciata and Acanthistius ocellatus (boulder-coral) or A. strigatus and Scorpis lineolata (pyurid habitat) fish species, respectively (Fig. 6). 


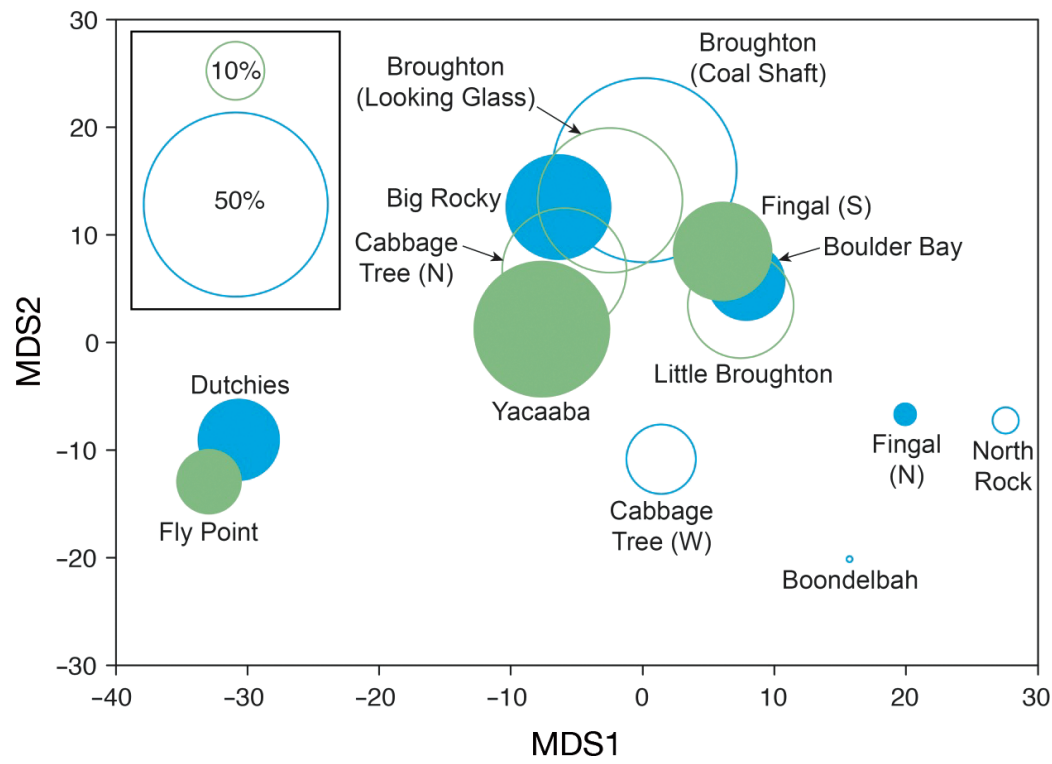

Fig. 5. Threshold-metric multi-dimensional scaling (MDS) of the site group centroids for benthic habitat composition during autumn. Bubbles are scaled to percent cover of canopy macroalgae (indicative sizes indicated in key). Zones are indicated by colour (green: no-take area; blue: partially protected area) and geomorphology is indicated by fill (filled: headland; unfilled: island)

\section{DISCUSSION}

Shallow rocky reef fish communities are under increasing pressure from a range of local threats that include overharvesting and habitat destruction. In locations where NTAs are placed and enforced, fish community composition - particularly targeted families and species - are expected to show a positive response (in terms of abundance and/or local recruitment) to reduced harvest pressure (Barrett et al. 2007). However, bottom-up effects from changing habitat conditions can exert strong influences on reef fish community composition across space and time (Curley et al. 2002, Fulton \& Bellwood 2004, Fulton et al. 2016, van Lier et al. 2017). In this subset of reefassociated species and sites, we found fish community composition did not significantly differ among NTAs and PPAs. Rather, the structure of the fish assemblages was more closely related to season and site-level differences in habitat condition and geomorphology, with a range of species-specific responses. The present study reinforces previous findings that rocky reef communities and fishery target families and species can vary considerably over fine and broad spatial scales in close association with their preferred habitats (Willis et al. 2003, Friedlander et al. 2010, Morton \& Gladstone 2011).

Spatial conservation and fisheries management is widely recognised as one approach to sustaining marine biodiversity alongside key ecosystem functions, goods and services (Halpern 2003, Lester \& Halpern 2008). However, the extent of zoning effects upon fish community composition and abundance can depend on a range of factors that relate to the size and age of the zones, level of voluntary compliance with the no-take regulations, as well as the range of ecological and environmental conditions (Edgar et al. 2014). Here, we were able to use a novel coupling of mini-BRUVs and habitat surveys to tease apart the relative influence of spatial factors to find that major variation occurred largely at the site level and was independent of differences in recreational fishing harvest restrictions via spatial zoning. Notably, the 2 management zones had common levels of habitat protection-this could explain the overlap in fish community structure when strong bottom-up habitat effects are operating on reef fish relative abundance in a heterogeneous seascape (Curley et al. 2013, Fulton et al. 2016). Essentially, this suggests that a representative areas approach has been achieved across these 2 MPA management zones, so that they capture similar mosaics of patch habitat variation. Moreover, our results suggest that fish assemblages around headlands and islands may be unique, and require a balanced level of protection in spatial management plans and zoning.

Environmental and MPA characteristics related to age, size and location have been shown to influence major changes in reef fish assemblages (GarcíaCharton et al. 2004, Edgar et al. 2014, Coleman et al. 2015). A key aspect of such studies has been partitioning the influence of human activities (e.g. harvest, point-source pollution) regulated by spatial management, from changes that arise from natural spatial and temporal variability (Malcolm et al. 2007, Curley et al. 2013). In specifically examining fisherytarget species within the PSGLMP, we found that there was no influence of NTAs on species targeted by fishers. These findings are contradictory to other studies of habitat in deeper waters of this and other temperate MPAs that have demonstrated higher abundance of fishery target species in NTAs (e.g. Kelaher et al. 2014, Harasti et al. 2018a,b, Malcolm et al. 2018). The present study assessed fish assemblages in much shallower waters than these previous 

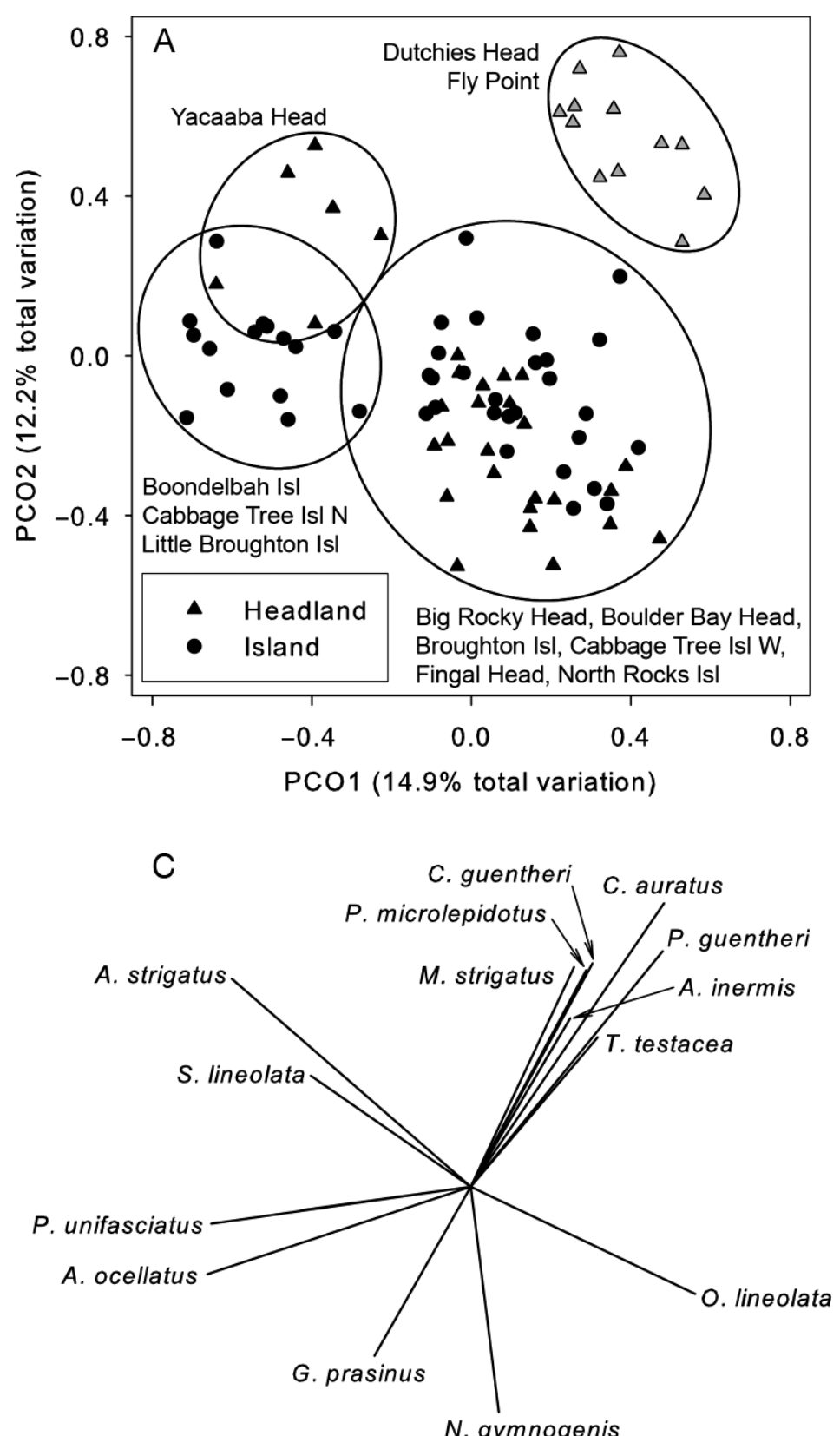

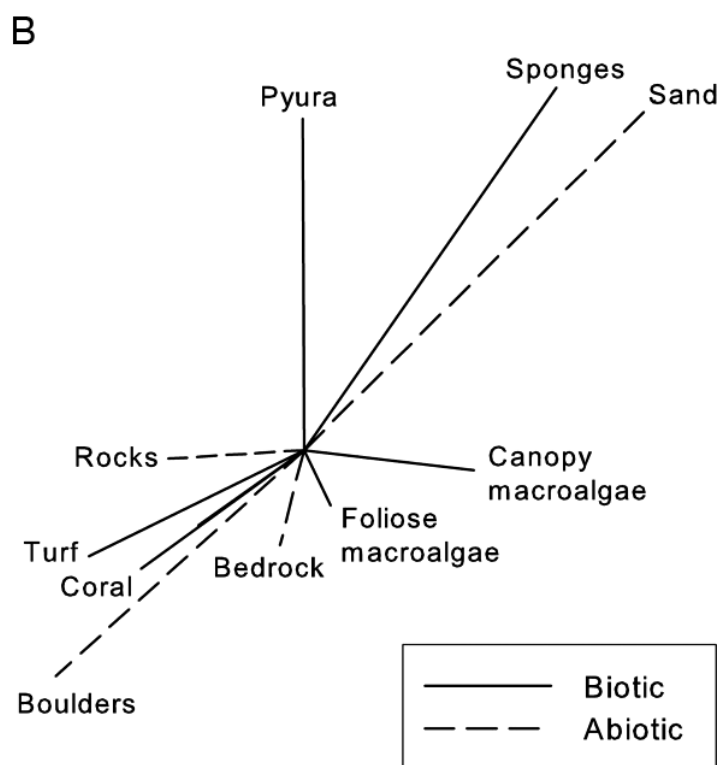

Fig. 6. Principal components ordination of 14 sites within the Port Stephens-Great Lakes Marine Park during the autumn sampling season according to (A) reef fish community structure (based on relative abundance, MaxN), which can be explained by vector overlays of the (B) benthic habitat composition within a $10 \times 10 \mathrm{~m}$ area around each mini-BRUV sampling station, and (C) key fish species (with 0.5 or greater Pearson's correlation with the ordination structure). Significant clustering in reef fish community structure is circled in A, with adjacent text indicating location of samples within each group. Inshore estuary headland sites are indicated with grey-filled symbols. Note that Fingal Head (North and South) and Broughton Island (Coal Shaft and Looking Glass) each have 2 sites. Full fish taxonomic names are provided in Table S1 in the Supplement studies, arguably in areas that are lightly or infrequently targeted by fishers around these islands and headlands. In addition, it has recently been shown within the marine park that there is a high level of illegal recreational fishing occurring within NTAs, causing a decline in fishery target species such as $C$. auratus (Harasti et al. 2019), and the impact of illegal recreational fishing in these shallow water NTAs is unknown.

Effects of spatial zoning on fish community composition can take time, especially when key components of the ecosystems have long generation and turnover times, which can mean that effects may not be apparent until sometime after an NTA is established (Curley et al. 2013, Edgar et al. 2014). Changes in the abundance of target species may take many decades to appear, especially for slow-growing and late-maturing species that have been heavily exploited (Babcock et al. 2010, Edgar et al. 2014). Changes in community structure could take many decades to mature after the cessation of harvest activity (Russ \& Alcala 2004). As such, the relatively young age of the PSGLMP (around $10 \mathrm{yr}$ at the time of this study) could mean it is too soon to detect major changes in 
target fish abundance and/or fish assemblages within NTAs or that illegal fishing activities are hindering recovery within the NTAs (Harasti et al. 2019). Previous evaluations have suggested return times for population recovery to virgin biomass can be in the order of 15 to $45 \mathrm{yr}$, depending on the demographics of the target species (Russ \& Alcala 2004, Russ et al. 2005, Edgar et al. 2009). Indeed, the longevity of some of the relevant species (e.g. O. lineolatus, $14 \mathrm{yr}$, Lek et al. 2012) suggests it may be some time before we are able to detect the full effect of NTAs on these shallow water rocky reef fish populations and communities.

Some fish families may not be strongly influenced by zoning effects. For example, the lack of a zoning effect for members of the Labridae family (i.e. $O$. lineolatus, $P$. laticlavius) is consistent with other studies on labrids, which are more strongly demersal and habitat-associated taxa (Fulton et al. 2016, van Lier et al. 2017). However, we note that previous size-based assessments for fishery-target species (such as $C$. auratus) indicate that populations within NTAs can have more large-bodied individuals than fished populations in open zones (Willis et al. 2003, Denny et al. 2004, Malcolm et al. 2015). We suggest future work should try to solve the logistical problems of surveying fish body sizes within these complex shallow reef habitats (particularly within kelp forests) to explore possible shifts in fish lengths across zones.

One important finding to emerge from this study was the importance of a site-level approach to spatial conservation and management that encompasses a range of geomorphological settings. In particular, we found the greatest amount of variation in the shallow reef fish community could be explained at the site level, however, sample season was an important axis of variation in the surveyed fish assemblages. High fish species richness was predominantly recorded across most sites in autumn, whilst fish community evenness was generally lower during autumn. Several theories have been proposed to explain temporal differences in fish communities, particularly for fishery-target species, such as seasonal increases in temperature driving spawning aggregations and movements between inshore and offshore reefs (Willis et al. 2003, Denny et al. 2004, Hamer \& Jenkins 2004, Smith et al. 2014). Species such as the shark Heterodontus portusjacksoni that were more abundant over spring can be related to the breeding season for the species (Powter \& Gladstone 2008). Of course, the present study was only able to assess seasonal differences within a single year, so further assessment of seasonality patterns among islands and headlands over several years is warranted. Nonetheless, our study highlights the need to be cautious about singleseason estimates of reef fish community structure, especially when exploring the effects of spatial zoning and other management interventions.

Habitat condition has also emerged as a key metric for considering how to apply spatial conservation and management plans to protect and enhance fish biodiversity and abundance. Habitat condition can have a major influence on reef fish distribution and abundance according to the particular habitat requirements of each species interacting with the availability of microhabitats among sites (Curley et al. 2002, Fulton et al. 2016, van Lier et al. 2017). These habitat effects can be particularly strong in specialist species that are found to strongly prefer certain microhabitat types (e.g. N. gymnogenis, O. lineolatus, Pictilabrus laticlavius and $O$. cyanomelas within kelp canopies; Morton \& Gladstone 2011, Fulton et al. 2016, van Lier et al. 2017). In the present study, variation in percent cover of canopy macroalgae (mostly Ecklonia, with some Sargassum and Phyllospora), sponges and boulder-rock regions (known as 'urchin barrens') were associated with differences in fish community structure. In a recent study in this region, Fulton et al. (2016) found that habitat availability was a key predictor of fish species distribution and abundance, particularly across areas dominated by canopy macroalgae, coral or boulder habitat. As such, areas that encompass a mosaic of these habitat types are likely to optimise the diversity and abundance of fish species (Fulton et al. 2016, van Lier et al. 2017). Spatial management, either for conservation or fisheries goals, should seek to include a mix of these habitat types in specific regions of concern to ensure there is the habitat base needed to sustain fish biodiversity, population replenishment and sustainable standing stocks. This becomes even more important when considering juvenile life-history stages, which often have highly specific habitat requirements that amplify the relationship between habitat availability and fish abundance across seascapes (e.g. juvenile labrids and kelp percent cover; Fulton et al. 2016).

The present study provides a baseline of fish responses to the early phases of spatial protection, which will allow comparisons to be made in the future if the existing NTAs remain in place and are effectively maintained at near-zero fishing pressure. This study found no evidence to suggest that shallow-water rocky reef fish communities differ across NTAs and PPAs within a relatively young coastal MPA. However, site-level differences related to geomorphology and habitat condition appear to be of major importance, which suggests spatial manage- 
ment approaches could be a key tool for conserving key ecological assets. Alongside a strong influence of local habitat composition, particularly canopy-forming macroalgae, seasonal effects were also important for drawing conclusions about the composition and abundance of target and non-target fish species within the marine park. Moreover, we found evidence to suggest that islands and headlands do not have homogeneous shallow-water fish communities, which means they should be considered as distinct units in the design and monitoring of spatial management zones. Ultimately, these biotic and abiotic conditions must be considered in any evaluation of the effects of marine protected area zoning on biodiversity and fish populations. Our findings also join a growing body of evidence that habitat-based measures (e.g. via a representative areas approach) can be effective for designing management strategies that seek to balance biodiversity conservation alongside other key uses and goals within a marine estate (Curley et al. 2002, Fulton et al. 2016).

Acknowledgements. We thank Roger Laird and Joshua van Lier for field assistance, Vincent Raoult and Tim Smith for helpful comments, and Joel Williams for assistance with some ot the figures. The University of Newcastle and NSW Department of Primary Industries provided funding with research conducted under NSW DPI Animal Care and Ethics Committee permit 10/09.

\section{LITERATURE CITED}

Anderson MJ, Ellingsen KE, McArdle BH (2006) Multivariate dispersion as a measure of beta diversity. Ecol Lett 9: 683-693

Anderson M, Gorley R, Clarke K (2008) PERMANOVA+ for PRIMER: guide to software and statistical methods. PRIMER-E, Plymouth, UK

Babcock RC, Shears NT, Alcala AC, Barrett NS and others (2010) Decadal trends in marine reserves reveal differential rates of change in direct and indirect effects. Proc Natl Acad Sci USA 107:18256-18261

Barrett NS, Edgar GJ, Buxton CD, Haddon M (2007) Changes in fish assemblages following 10 years of protection in Tasmanian marine protected areas. J Exp Mar Biol Ecol 345:141-157

Boubekri I, Djebar AB (2016) Marine protected areas in Algeria: Future marine protected area of 'Taza' (SW Mediterranean), continuing challenges and new opportunities facing an integrated coastal management. Ocean Coast Manage 130:277-289

Cappo M, Speare P, De'ath G (2004) Comparison of baited remote underwater video stations (BRUVS) and prawn (shrimp) trawls for assessments of fish biodiversity in inter-reefal areas of the Great Barrier Reef Marine Park. J Exp Mar Biol Ecol 302:123-152

Clarke KR, Warwick RM (2001) Changes in marine communities: an approach to statistical analysis and interpretation. PRIMER-E Ltd, Plymouth
Coleman MA, Bates AE, Stuart-Smith RD, Malcolm HA and others (2015) Functional traits reveal early responses in marine reserves following protection from fishing. Divers Distrib 21:876-887

Coleman MA, Jordan A, Kelaher BP, Ingleton T, Davies PL, Millar RB (2016) Remotely sensed habitat variables are poor surrogates for functional traits of rocky reef fish assemblages. Environ Conserv 43:368-375

Curley BG, Kingsford MJ, Gillanders BM (2002) Spatial and habitat-related patterns of temperate reef fish assemblages: implications for the design of Marine Protected Areas. Mar Freshw Res 53:1197-1210

Curley BG, Glasby TM, Curley AJ, Creese RG, Kingsford MJ (2013) Enhanced numbers of two temperate reef fishes in a small, partial-take marine protected area related to spearfisher exclusion. Biol Conserv 167:435-445

* Davis TR, Harasti D, Kelaher B, Smith SD (2016) Diversity surrogates for estuarine fish assemblages in a temperate estuary in New South Wales, Australia. Reg Stud Mar Sci $7: 55-62$

*Day JC (2002) Zoning - lessons from the Great Barrier Reef Marine Park. Ocean Coast Manage 45:139-156

*Denny CM, Willis TJ, Babcock RC (2004) Rapid recolonisation of snapper Pagrus auratus: Sparidae within an offshore island marine reserve after implementation of notake status. Mar Ecol Prog Ser 272:183-190

Edgar GJ, Russ GR, Babcock RC (2007) Marine protected areas. PSZNI: Mar Ecol 27:533-555

Edgar GJ, Barrett NS, Stuart-Smith RD (2009) Exploited reefs protected from fishing transform over decades into conservation features otherwise absent from seascape. Ecol Appl 19:1967-1974

Edgar GJ, Stuart-Smith RD, Willis TJ, Kininmonth S and others (2014) Global conservation outcomes depend on marine protected areas with five key features. Nature 506:216-220

Friedlander AM, Sandin SA, Demartini EE, Sala E (2010) Spatial patterns of the structure of reef fish assemblages at a pristine atoll in the central Pacific. Mar Ecol Prog Ser 410:219-231

Fulton CJ, Bellwood DR (2004) Wave exposure, swimming performance, and the structure of tropical and temperate reef fish assemblages. Mar Biol 144:429-437

*Fulton CJ, Noble MN, Radford B, Gallen C, Harasti D (2016) Microhabitat selectivity underpins regional indicators of fish abundance and replenishment. Ecol Indic 70:222-231

*Gaines SD, White C, Carr MH, Palumbi SR (2010) Designing marine reserve networks for both conservation and fisheries management. Proc Natl Acad Sci USA 107: 18286-18293

* García-Charton JA, Pérez-Ruzafa Á, Sánchez-Jerez P, BayleSempere JT, Reñones O, Moreno D (2004) Multi-scale spatial heterogeneity, habitat structure, and the effect of marine reserves on Western Mediterranean rocky reef fish assemblages. Mar Biol 144:161-182

* Habtemariam BT, Fang Q (2016) Zoning for a multiple-use marine protected area using spatial multi-criteria analysis: the case of the Sheik Seid Marine National Park in Eritrea. Mar Policy 63:135-143

Halpern BS (2003) The impact of marine reserves: do reserves work and does reserve size matter? Ecol Appl 13:117-137

*Halpern BS, Warner RR (2002) Marine reserves have rapid and lasting effects. Ecol Lett 5:361-366

*Hamer PA, Jenkins GP (2004) High levels of spatial and temporal recruitment variability in the temperate sparid Pagrus auratus. Mar Freshw Res 55:663-673 
Harasti D, Davis TR, Jordan A, Erskine L, Moltschaniwskyj $N$ (2019) Illegal recreational fishing causes a decline in a fishery targeted species (snapper: Chrysophrys auratus) within a remote no-take marine protected area. PLOS ONE 14:e0209926

Harasti D, Malcolm H (2013) Distribution, relative abundance and size composition of the threatened serranid Epinephelus daemelii in New South Wales, Australia. J Fish Biol 83:378-395

Harasti D, Gallen C, Malcom H, Tegart P, Hughes B (2014) Where are the little ones: distribution and abundance of the threatened serranid Epinephelus daemelii (Günther, 1876) in intertidal habitats in New South Wales, Australia. J Appl Ichthyol 30:1007-1015

Harasti D, Malcolm H, Gallen C, Coleman MA, Jordan A, Knott NA (2015) Appropriate set times to represent patterns of rocky reef fishes using baited video. J Exp Mar Biol Ecol 463:173-180

*Harasti D, Davis TR, Mitchell E, Lindfield S, Smith SDA (2017) A tale of two islands: decadal changes in rocky reef fish assemblages following implementation of notake marine protected areas in New South Wales, Australia. Reg Stud Mar Sci 18:229-236

Harasti D, Williams J, Mitchell E, Linfield S, Jordan A (2018) Increase in relative abundance and size of snapper Chrysophrys auratus within partially-protected and notake areas in a temperate marine protected area. Front Mar Sci 5:1-12

Kaplan KA, Yamane L, Botsford LW, Baskett ML, Hastings A, Worden S, Wilson White J (2019) Setting expected timelines of fished population recovery for the adaptive management of a marine protected area network. Ecol Appl 29:e01949

Kelaher BP, Coleman MA, Broad A, Rees MJ, Jordan A, Davis AR (2014) Changes in fish assemblages following the establishment of a network of no-take marine reserves and partially-protected areas. PLOS ONE 9: e85825

Kek E, Fairclough DV, Hall NG, Hesp SA, Potter IC (2012) Do the maximum sizes, ages and patterns of growth of three reef-dwelling labrid species at two latitudes differ in a manner conforming to the metabolic theory of ecology? J Fish Biol 81:1936-1962

Lester SE, Halpern BS (2008) Biological responses in marine no-take reserves versus partially protected areas. Mar Ecol Prog Ser 367:49-56

Lester SE, Halpern BS, Grorud-Colvert K, Lubchenco J and others (2009) Biological effects within no-take marine reserves: a global synthesis. Mar Ecol Prog Ser 384:33-46

* Malcolm HA, Gladstone W, Lindfield S, Wraith J, Lynch TP (2007) Spatial and temporal variation in reef fish assemblages of marine parks in New South Wales, Australia baited video observations. Mar Ecol Prog Ser 350:277-290

Malcolm HA, Schultz AL, Sachs P, Johnstone N, Jordan A (2015) Decadal changes in the abundance and length of snapper (Chrysophrys auratus) in subtropical marine sanctuaries. PLoS One 10:e0127616

Malcolm HA, Jordan A, Creese RG, Knott NA (2016) Size and age are important factors for marine sanctuaries: evidence from a decade of systematic sampling in a subtropical marine park. Aquat Conserv 26:1090-1106

Malcolm HA, Williams J, Schultz AL, Nielson J and others (2018) Targeted fishes are larger and more abundant in 'no-take' areas in a subtropical marine park. Estuar Coast Shelf Sci 212:118-127
Miller KI, Russ GR (2014) Studies of no-take marine reserves: methods for differentiating reserve and habitat effects. Ocean Coast Manage 96:51-60

*Molloy PP, McLean IB, Côté, IM (2009) Effects of marine reserve age on fish populations: a global meta-analysis. J Appl Ecol 46:743-751

Morton JK, Gladstone W (2011) Spatial, temporal and ontogenetic variation in the association of fishes (family Labridae) with rocky-reef habitats. Mar Freshw Res 62:870-884

* Noble MM, Van Laake G, Berumen ML, Fulton CJ (2013) Community change within a Caribbean coral reef marine protected area following two decades of local management. PLOS ONE 8:e54069

NSW Marine Parks Authority (2013) Port Stephens-Great Lakes Marine Park Zoning Plan User Guide. https:// www.dpi.nsw.gov.au/fishing/marine-protected-areas/ marine-parks/port-stephens-marine-park

* Powter DM, Gladstone W (2008) The reproductive biology and ecology of the Port Jackson shark Heterodontus portusjacksoni in the coastal waters of eastern Australia. J Fish Biol 72:2615-2633

* Rodwell LD, Barbier EB, Roberts CM, Mcclanahan TR (2003) The importance of habitat quality for marine reserve fishery linkages. Can J Fish Aquat Sci 60:171-181

* Russ GR, Alcala AC, Maypa AP (2003) Spillover from marine reserves: the case of Naso vlamingii at Apo Island, the Philippines. Mar Ecol Prog Ser 264:15-20

* Russ GR, Alcala AC (2004) Marine reserves: long-term protection is required for full recovery of predatory fish populations. Oecologia 138:622-627

* Russ GR, Alcala AC (2011) Enhanced biodiversity beyond marine reserve boundaries: The cup spillith over. Ecol Appl 21:241-250

* Russ GR, Stockwell B, Alcala AC (2005) Inferring versus measuring rates of recovery in no-take marine reserves. Mar Ecol Prog Ser 292:1-12

* Sciberras M, Jenkins SR, Mant R, Kaiser MJ, Hawkins SJ, Pullin AS (2015) Evaluating the relative conservation value of fully and partially protected marine areas. Fish Fish 16:58-77

Shears NT, Babcock RC (2002) Marine reserves demonstrate top-down control of community structure on temperate reefs. Oecologia 132:131-142

Smith ANH, Anderson MJ (2016) Marine reserves indirectly affect fine-scale habitat associations, but not overall densities, of small benthic fishes. Ecol Evol 6:6648-6661

Smith ANH, Anderson MJ, Millar RB, Willis TJ (2014) Effects of marine reserves in the context of spatial and temporal variation: an analysis using Bayesian zero-inflated mixed models. Mar Ecol Prog Ser 499:203-216

* Teixeira-Neves T, Neves L, Araújo F (2015) Hierarchizing biological, physical and anthropogenic factors influencing the structure of fish assemblages along tropical rocky shores in Brazil. Environ Biol Fishes 98:1645-1657

* van Lier JR, Harasti D, Laird R, Noble MM, Fulton CJ (2017) Importance of soft canopy structure for labrid fish communities in estuarine mesohabitats. Mar Biol 164:1-11

WWillis TJ, Millar RB, Babcock RC (2003) Protection of exploited fish in temperate regions: high density and biomass of snapper Pagrus auratus (Sparidae) in northern New Zealand marine reserves. J Appl Ecol 40:214-227

Wilson SK, Depczynski M, Holmes TH, Radford B, Tinkler P, Fulton CJ (2017) Climatic conditions and nursery habitat quality provide indicators of reef fish recruitment strength. Limnol Oceanogr 62:1868-1880 